\title{
11. "SEEING IS BELIEVING": THE IMPORTANCE OF VISUAL FACTORS IN MUSIC PERFORMANCE ASSESSMENT
}

\author{
Dorina Geta Iușcă ${ }^{274}$
}

\begin{abstract}
The criteria recommended for the performance of internal assessment are the ones included in the national model for school inspection applied by the inspectors in the school inspectorate or the Ministry of Education (with subsequent names) who carry out internal assessments. Educational establishments can also decide on certain additional criteria - in line with the specific needs. All educational establishments must perform the annual assessment of activity, regarding school development, educational programs, curricular and extracurricular activities, quality of the teaching-learning process, human resources development, relations with the community and European dimension in the education offered. A tricky problem is represented by the specific assessment of Children Centres and Clubs that carry out non-formal activity, without school programs and handbooks approved by the Ministry of Education. Carrying out an analysis of the manner of assessing formal and non-formal educational units, the need to readjust the internal and external assessment was identified. At the level of school inspectorates, school inspection is carried out by a team consisting of specialised inspectors who know the specificity of those educational units. The main problem is represented by the external assessment carried out by ARACIP with the help of standard specific means: fields, indicators, reference descriptors and specific descriptors. Through the study performed, a series of proposals on the beneficial amendments for the quality assessment within Children Centres and Clubs is identified.
\end{abstract}

Key words: artistic education, quality, non-formal education

\section{Introduction}

Artistic experience and research have shown that the way musical performance is presented to evaluators tends to significantly influence assessment scores. Most educational or professional assessments of music performance are made in relation to live performances. This situation often creates standard evaluation errors which have been analyzed in educational literature: the contrast effect (overrating or underrating performers according to their succession, therefore a mediocre performer may get higher scores when he follows a very unprepared one, and lower scores when he follows an exceptional one), the order effect (underrating performers according to their position - performers which are rated later in line tend to get lower scores due to fatigue), the hallo effect (extending a sequential feature to the whole performance - for example the correct or incorrect position of the instrument may wrongfully be extended to the way evaluators assess the whole performance), the Pygmalion effect (created by the

\footnotetext{
274 Associate Professor PhD., "George Enescu” National University of Arts from Iaşi, Romania, email: dorinaiusca@yahoo.com
} 
expectancies evaluators tend to develop knowing certain previous information about performers - such as the prestige of performers' teacher, musical institution or family) and the logic error (the substitution of certain evaluation criteria with other less relevant criteria such as the way performers are dressed or move on the stage). Moreover, national and international competitions tend to evaluate large numbers of performers on long periods of time. This context amplifies the risks of misevaluation and of subjective hierarchies due to attention fluctuations and fatigue.

\section{Audio versus audio-video music performance assessments}

In order to reduce evaluation errors associated with live performances, many researchers suggest evaluating music performance recordings. Radocy (1989 apud Forbes, 1994) says that contrast and order effects may be reduced through the use of recordings which can be played repeatedly and in different orders. Also, the assessment of audio-only music performances eliminates all the errors associated to the visual information about performers. This advantage related to audio-only performance assessments led to the adoption of an interesting practice in auditions, practice that is still followed in important cultural institutions: singing or playing the instrument behind a curtain. Therefore, not seeing the performer is considered to be an objective and correct manner to evaluate orchestra and choir members, or vocal and instrumental soloists.

Such a practice caught the attention of music psychology researchers who wanted to investigate to way assessment scores vary due to the presence of visual information about the performers. For example, Gillespie (1997) has developed an experiment where a number of violinists and violists have been recorded in audio-video and audio-only formats. The evaluators assessed their vibrato quality in both formats. First, they assessed the audio-video recordings and after six months they assessed the audio-only recordings. Statistical analysis has revealed that the same musical performance has received higher scores when assessed in audio-video format in comparison with audio-only formats.

In 2008, an American researcher (Lychner) has discovered that both musicians and non-musicians tend to develop different aesthetic reactions to music when it is accompanied or not by visual information. The concept of aesthetic reaction has been defined by the emotional tension subjects perceive during audition / video-audition of a certain musical recording and it has been measured using a Continuous Response Digital Interface. Lychner's study revealed a stronger aesthetic reaction of non-musicians (compared to musicians) to audio-video recordings. Audio-only music recordings have generated the same level of aesthetic reaction in musicians and non-musicians. Also, the nonmusicians Continuous Response Digital Interface profile has shown more abrupt peaks in comparison with professional musicians. In conclusion, Lychner has proved that listening or looking at certain country music melodies may develop different emotional effects according to the public musical experience. 
A Canadian study (Wapnick et al, 2004) has also demonstrated the importance of recordings format (audio-video versus audio-only) when evaluating classical music performance. Researchers have recorded 18 professional pianists playing in an important piano competition. The audio-only recordings have been assessed by 95 evaluators and the audio-video recordings have been assessed by another group of 132 evaluators. Wapnick and collaborators have discovered that the audio-video performances have received higher scores than the audio-only recordings, therefore confirming previous findings (Wapnick et al, 1998; Wapnick et al, 2000) that discovered evaluators tendency to overestimate music performers that are also seen, not only heard. These results are available for all musicians except pianists that have not been affected by the presentation format. Pianists evaluators have not been influenced by presentation format and rated similarly audio-only and audio-video recordings. Unlike pianists, all the other musicians without piano playing experience rated audio-video recordings higher than audio-only recordings (Wapnick et al, 2004).

Ryan \& Costa-Giomi (2004) have revealed that the presentation format influence not only score variability but also inter-rater consensus. In a study conducted on pianists, audio-only recordings got a lower internal consistency between evaluators. Researchers have explained this result by the fact that audiovideo recordings offer more information about performers' expressive intentions through facial expressions and gestures, which in turn transmit a more obvious message to the evaluators. In the end, it remains to be discussed if by evaluating audio-only performances competition juries lose some important music performance criteria such as stage presence, instrument position, facial and body expression which may bring a more complete picture of the music performance itself.

\section{Performers' visual appearance}

The idea that a person's visual appearance impacts his or her life in a significant manner has repeatedly been demonstrated. The general impression about a person or an object influence us to make important decisions in every aspect of our life. Therefore, it is expected that the way an individual look to determine others' appreciations about his or her abilities. Many studies have shown the significant effect of attractiveness in receiving better chances in being admitted to college (Shahani et al, 1993 apud Wapnick et al, 1998) or in getting a job (Cann et al, 1981 apud Wapnick et al, 1998). In general, attractive people are seen as being more intelligent and more competent socially (Eagly et al, 1991 apud Griffiths, 2009). Also, teachers who work with middle school and high school students have lower expectations from less attractive students (Adams, 1978 apud Wapnick et al, 1998). In the musical field, it has been suggested that the visual information of performers have a considerable impact on the way they are evaluated as musicians. Most studied variables focused on gender, race, stage costumes, attractiveness and movements during music performance. 
Wapnick and collaborators $(1998,2000)$ have revealed evaluators' tendency (men and women alike) to overrate men cellists. Moreover, attractive men received higher scores than less attractive men. Also, attractive men have been rated higher than attractive women. Thus, we can talk about a significant effect of gender and attractiveness on music performance assessment. Interestingly, researchers have found that attractive men have received higher scores in music performance both in audio-video and audio-only presentation format. When trying to explain this paradox, researchers have pointed out higher educational opportunities and more encouraging social interaction that attractive men benefit from at an early age and during their instrumental training.

Ryan \& Costa-Giomi (2004) have noticed that attractiveness affects differently men and women performers. They have found that the higher scores have been given to attractive women and unattractive men. This visual effect had a better impact on good and very good pianists, and was not visible on medium and unprepared pianists. Ryan \& Costa-Giomi (2004) have also discovered that evaluators' gender is also relevant. Therefore, men evaluators rated attractive performers lower than women evaluators. These results have been confirmed in an ulterior study (Ryan et al, 2006) where men evaluators underrated attractive and well-dressed performers more than women evaluators did. It may be because the two genders have different perspectives on what it means to be attractive. There is also a race influence on music performance assessment. Elliott's study (1995/1996 apud Thompson \& Williamon, 2003) have found that Afro-American performers have received lower scores than their Caucasian counterparts. In another research McCray (1993 apud Berminghan, 2000) have discovered that evaluators tend to give higher sores to the same race performers. This effect is more obvious in the case of Afro-American performers.

Griffiths (2009) has revealed that the concert outfit may also influence music performance assessment. The researcher has asked a group of 33 musicians to rate a violinists' performance level while dressed in three different outfits: a strapless short club dress, a three-quarter sleeves long concert dress and an outfit made of a t-shirt and blue jeans. The evaluators did not know that the audio recording was exactly the same in all three situations. Results have shown that the violinist has got significantly higher scores for the music performance where she was dressed in the long concert dress and significantly lower scores when dressed in the club short dress. Trying to explain the obtained statistical data, the researcher pointed out that the short dress may distract evaluators' attention from the music performance to other non-relevant elements such as body shape or sexual clues which modifies evaluators' mental state and concentration. Also, the violinist explained that she felt most comfortable playing in the concert dress and in turn this fact amplified her movement opportunities, letting her show a higher level of confidence and expression. Nevertheless, the best explanation for the results pointed out that the concert dress builds a specific image in the evaluators' mind, a specific image associated with classical music performance success and 
prestige.

Lastly, the level of movement during music performance may also influence music performance assessment. Nevertheless, playing an instrument is fundamentally dependent on the way performer moves. Beside the technical movements necessary for playing the instrument, the performer also shows a series of psychological states of which he is more or less conscious. Certain face or body movements during music performance are indicative of performer's expressive abilities. Davidson (1994 apud Juchniewicz, 2008) suggested that, in order to determine a music performer's expressive intentions, the visual clues are more effective than the audio clues.

In 2008, Juchniewicz has conducted a study where 112 musicians have been asked to rate a pianist's music performance level during three experimental conditions: "no movements" (a specific situation where the pianist had to limit his movements only to the technical ones), "face movements" (where the expressive intentions were seen only on the facial movements) and "body movements" (where the pianist expressed his performance perspective using his whole body). Evaluators didn't know that the audio recording was exactly the same in all three conditions. Juchniewicz has discovered that the pianist has received significantly different scores in all three experimental conditions. He has got the highest scores in the "body movement" condition, as the evaluators (all musicians) considered this performance to be the most expressive. Still, Davidson (2007) points out that not all expressive movements lead to higher music performance, but only those who match the repertoire, the performer's interpretative perspective and the musical style. In order to widen music students' expressive movements, Seitz (2005) suggests the Dalcroze method of rhythm development by using the whole body. These exercises help coordinate both hands, arms, feet and voice according to certain musical elements.

\section{Conclusions}

In conclusion, we have to take into account that certain visual aspects of music performers have a significant impact on their performance assessment. By knowing this fact, soloists, conductors, music teachers and parents may use the experimental data in order to manipulate elements related to gender, race, attractiveness, outfit and movements, to receive higher score auditions, recitals, concerts and national and international music competitions. A correct image of the performer may increase his or her chances of success, in educational, cultural or social contexts. The educational implications of this study extend to the necessity for the teachers to make music students aware of the way they dress or move in evaluative situations.

\section{References}

1. Adams, G. (1978). Racial Membership and Physical Attractiveness Effects on Preschool Teachers' Expectations. Child Study Journal, 8, 29-41 
2. Cann, A., Siegfried, W., \& Pearce, L. (1981). Forced Attention to Specific Applicant Qualifications: Impact on Physical Attractiveness and Sex of Applicant Bias. Personnel Psychology, 34, 65-75

3. Davidson, J. W. (1994). Which Areas of a Pianist's Body Convey Information about Expressive Intention to an Audience? Journal of Human Movement Studies, 6, 279-301 4. Davidson, J. W. (2007). Qualitative Insights into the Use of Expressive Body Movement in Solo Piano Performance: A Case Study Approach. Psychology of Music, 35(3), 381-401

5. Eagly, E. H., Ashmore, R. D., Makhijani, M. G., \& Longo, L. C. (1991). What Is Beautiful Is Good, But...: A Meta-Analytic Review of Research on the Physical Attractiveness Stereotype. Psychological Bulletin, 110, 109-128

6. Elliott, C. A. (1995/1996). Race and Gender as Factors in Judgments of Musical Performance. Bulletin of the Council for Research in Music Education, 127, 50-56

7. Forbes, G. W. (1994). Evaluative Music Festivals and Contests - Are They Fair? Update: Applications of Research in Music Education, 1, 16-20

8. Gillespie, R. (1997). Ratings of Violin and Viola Vibrato Performance in AudioOnly and Audiovisual Presentations. Journal of Research in Music Education, 45(2), 212-220

9. Griffiths, N. K. (2009). "Posh Music Should Equal Posh Dress": An Investigation into the Concert Dress and Physical Appearance of Female Soloists. Psychology of Music, 1-19

10. Juchniewicz, J. (2008). The Influence of Physical Movement on the Perception of Musical Performance. Psychology of Music, 36(4), 417-427

11. Lychner, J. A. (2008). A Comparison of Non-Musicians' and Musicians' Aesthetic Response to Music Experienced with and without Video. International Journal of Music Education, 26(1), 21-32

12. McCray, J. (1993). Effects of Listeners' and Performers' Race on Music Preferences. Journal of Research in Music Education, 41(3), 200-211

13. Radocy, R. E. (1989). On Quantifying the Uncountable in Music Behavior. Bulletin of the Council for Research in Music Education, 88, 22-31

14. Ryan, C., \& Costa-Giomi, E. (2004). Attractiveness Bias in the Evaluation of Young Pianists' Performances. Journal of Research in Music Education, 52(2), 141-154

15. Shahani, C., Dipboye, R., \& Gehrlein, T. (1993). Attractiveness Bias in the Interview: Exploring the Boudaries of an Effect. Basic and Applied Social Psychology, $14,317-328$

16. Wapnick, J., Mazza, J. K., \& Darrow, A. A. (1998). Effects of Performer Attractiveness, Stage Behaviour, and Dress on Violin Performance Evaluation. Journal of Research in Music Education, 46(4), 510-521

17. Wapnick, J., Mazza, J. K., \& Darrow, A. A. (2000). Effects of Performer Attractiveness, Stage Behaviour, and Dress on Children's Piano Performances. Journal of Research in Music Education, 48(4), 323-336

18. Wapnick, J., Ryan, C., Lacaille, N., \& Darrow, A. A. (2004). Effects of Selected Variables on Musicians' Ratings of High-Level Piano Performances. International Journal of Music Education, 22(1), 7-20 